\title{
MODELLING URBAN NOISE IN CITYGML ADE: CASE OF THE NETHERLANDS
}

\author{
K. Kumar*, H. Ledoux, T.J.F. Commandeur, J. E. Stoter
}

3D Geoinformation, Delft University of Technology, The Netherlands - (k.kavisha, h.ledoux, t.j.f.commandeur, j.e.stoter)@tudelft.nl

KEY WORDS: Urban noise, noise maps, CityGML, ADE.

\begin{abstract}
:
Road traffic and industrial noise has become a major source of discomfort and annoyance among the residents in urban areas. More than $44 \%$ of the EU population is regularly exposed to road traffic noise levels over $55 \mathrm{~dB}$, which is currently the maximum accepted value prescribed by the Environmental Noise Directive for road traffic noise. With continuously increasing population and number of motor vehicles and industries, it is very unlikely to hope for noise levels to diminish in the near future. Therefore, it is necessary to monitor urban noise, so as to make mitigation plans and to deal with its adverse effects. The 2002/49/EC Environmental Noise Directive aims to determine the exposure of an individual to environmental noise through noise mapping. One of the most important steps in noise mapping is the creation of input data for simulation. At present, it is done semi-automatically (and sometimes even manually) by different companies in different ways and is very time consuming and can lead to errors in the data. In this paper, we present our approach for automatically creating input data for noise simulations. Secondly, we focus on using 3D city models for presenting the results of simulation for the noise arising from road traffic and industrial activities in urban areas. We implemented a few noise modelling standards for industrial and road traffic noise in CityGML by extending the existing Noise ADE with new objects and attributes. This research is a steping stone in the direction of standardising the input and output data for noise studies and for reconstructing the 3D data accordingly.
\end{abstract}

\section{INTRODUCTION}

Urban noise has become an increasingly omnipresent and potentially harmful form of environmental pollution globally. Automobiles, industrial activities and use of public address systems like loudspeakers - all contribute to urban noise. It adversely affects health, peace of mind and well-being of individuals. Regular exposure to higher noise levels can cause insomnia, depression, deafness, reduced productivity, or in extreme cases, can cause mental breakdown. More than $44 \%$ of the EU population (nearly 210 million people) is regularly exposed to road traffic noise over $55 \mathrm{~dB}$, the level recognized to pose a serious health hazard by WHO (Den Boer and Schroten, 2007). The ill effects of urban noise on the health of its citizens are of major concern for the government of Netherlands. According to a recent study, almost 600 people die every year in Netherlands from the harmful effects of noise pollution (Adriana Stuijt, 2009). With continously increasing population and flow of motor vehicles, there is very little hope for noise levels to diminish in the near future.

In order to have a common management plan for handling urban noise, the European Union formulated a 2002/49/EC Environmental Noise Directive (END). The main objective of the directive is to determine the exposure of an individual to environmental noise through noise mapping and to ensure that the information on environmental noise and its effects is made available to the public (Directive, 2002). The process of noise mapping involves three major steps: creating the input data for simulation, determining the noise levels and their effects and finally storing/presenting the results in a comprehensive way (de Kluijver and Stoter, 2003). One of the most important steps in any noise study is the creation of input data used for simulation. Two sets of data are required for effective noise mapping: (1) data related to the source of noise (e.g. number of vehicles, speed of vehicles, operating hours of machinery, etc.) and obstructions in the path of noise (e.g. height of noise barriers and buildings) (2) geographic locations of people (e.g. buildings) to test their sensitivity to noise (de Kluijver and Stoter,

${ }^{*}$ Corresponding author
2003). At present, there is an exenstive collection of geographical data sources available which can be used for noise mapping e.g. $\mathrm{BGT}^{1}, \mathrm{TOP}_{10 \mathrm{NL}^{2}}, \mathrm{AHN}^{3}$. However, the problem lies in their integration due to differences in their standards, formats and scales. Modelling input data for simulation is an important task and at present it is done semi-automatically (and sometimes even manually) by different companies in different ways which is very time consuming and can lead to errors in the data. In this research, we have tried to automate this process of data creation for noise simulation.

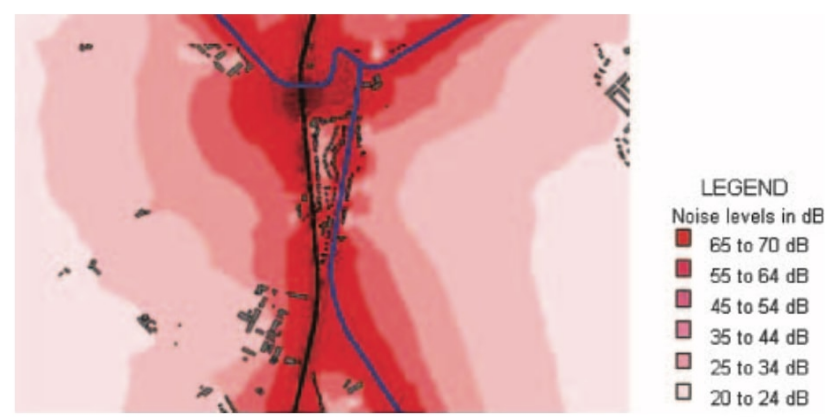

Figure 1: 2D noise map (de Kluijver and Stoter, 2003)

Another main component of this research is the storage and representation of the results of noise simulation in a logical and consistent manner. One way can be to produce noise maps (as directed by the END). The noise maps serve as an important source of information to know which areas are affected by noise. However, the noise maps which currently exist and are recommended by the END are in 2D as shown in Figure 1. These 2D noise maps

\footnotetext{
${ }^{1}$ https://www.pdok.nl/n1/producten/pdok-downloads/downloadbasisregistratie-grootschalige-topografie

${ }^{2}$ https://www.pdok.nl/nl/producten/pdok-downloads/basisregistratietopografie/topnl/topnl-actueel/top10nl

${ }^{3}$ https://www.pdok.nl/nl/ahn3-downloads
} 
represent noise levels at one particular height (e.g. 4 metres as suggested by the END). However, this information is not suffucient to map the effects of noise at higher floors of a building. Many individuals live in high rise buildings and at the same time, are also affected by noise. The variations in noise levels at different heights and due to the presence of other features like buildings and noise barriers in the path of noise propagation cannot be properly modelled using 2D noise maps. The variations are quite large when the source is located quite close to the building or when noise barriers are present. In order to deal with these problems, it is required to create noise maps which can provide complete information for the variations in noise levels. This is possible by using 2.5D and 3D city models for mapping noise. At present, cities like Hong Kong (Law et al., 2011) and Paris (Butler, 2004) are using 3D city models for noise mapping. Stoter et al. (2008) discussed at length the importance of using 3D noise maps for noise impact studies. We focus here on using 3D representations for presenting the results of simulation for the noise arising from road traffic and industrial activities in urban areas. In 3D we can map the noise levels at different heights at a particular location $(x, y)$ (e.g. at different floors of a building) (Figure 2). For 3D storage and representation of noise data, we see no better solution than the international 3D GIS standard CityGML (Groger et al., 2012). CityGML provides geometric-semantic coherence when it comes to representing 3D city models (Stadler and Kolbe, 2007). To comply with the END, a CityGML noise application schema

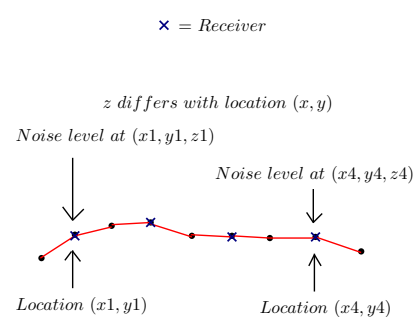

$2.5 \mathrm{D}$

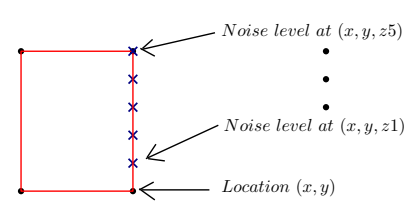

$3 D$
Figure 2: Noise mapping in 2D (left) and 3D (right)

was developed by the Institute of Geodesy and Geoinformation University of Bonn and the Special Interest Group SIG 3D of GDI NRW (Groger et al., 2012). It is based on the concept of ADE (Application Domain Extension) which involves extending the existing CityGML schema by adding new classes and objects. The main advantage of using ADEs is that we can extend the CityGML schema with application specific data and still maintain semantic interoperability. Many cities in the state of North-Rhine Westphalia, Germany have implemented their 3D noise models based on this CityGML Noise ADE (Czerwinski et al., 2007). However, we noticed that the current Noise ADE has some limitations. For instance, it only represents noise data arising from road traffic and railways and does not support industrial noise (see Section 3 for all the details). We aim at implementing a few noise modelling standards for industrial and road traffic noise in CityGML by extending the ADE with new classes and objects. This extension to the Noise ADE is modelled in accordance with the Dutch calculation methods for road traffic and industrial noise The generated data is represented in 3D using this extended ADE. To summarize, we present in this paper:

1. our approach for automatically creating input data for noise simulations. In Section 2, we describe our experience with Dutch noise modelling standards and simulation software, input requirements and how we automatically created the inputs for noise simulation.

2. our implementation of noise modelling standards for industrial and road traffic noise in the form of an extended City-
GML Noise ADE. We describe our ADE modelling approach in Section 3.

The aim is to to standardise the input and output data for noise simulation in order to be able to compare the outcomes of different noise studies and to assure that different noise studies using the same simulation method yield the same results.

\section{MODELLING THE INPUTS FOR NOISE SIMULATION}

\subsection{Noise input requirements and standards}

For computing the noise levels of a particular region, both thematic and geographical data of the region are required. For instance, computation of road traffic noise requires information like location and height of buildings, flow of traffic, percentage distribution of vehicles on road (light vehicles, heavy vehicles), speed limits of vehicles, type of road surface and information about noise barriers. Computing noise levels for the industries require information like type of noise source (point source or a surface source like radiating facade/roof), operating hours of machinery, noise barriers, location of buildings, etc. The noise levels are usually calculated separately for the day (06.00- 18.00), the evening (18.00-22.00) and the night (22.00-06.00) (Directive, 2002). There are several noise calculation methods followed in Netherlands (see Table 1), here we focus mainly on implementing and modelling inputs according to Wegverkeerslawaai $R M W-2012$ (VROM, 2015) for road traffic noise and Industrielawaai IL-HR-13-10/HMRI (VROM, 1981) for industrial noise. For a more detailed analysis, we prefer noise calculations at over a wide frequency range (as suggested by Dutch noise calculation methods) i.e. 9 octave bands with central frequencies of $31 \mathrm{~Hz}, 63 \mathrm{~Hz}, 125 \mathrm{~Hz}, 250 \mathrm{~Hz}, 500 \mathrm{~Hz}, 1 \mathrm{kHz}, 2 \mathrm{kHz}$, $4 \mathrm{kHz}$ and $8 \mathrm{kHz}$ (Daikin Applied, 2014).

\section{\# Noise calculation Description} methods

1 Industrielawaai IL Dutch industrial noise calculation

Industrielawaai windturbines

3 Industrie en wegver- International industrial and road keerslawaai ISO traffic noise calculation method 9613.1/2

4 Wegverkeerslawaai Dutch road traffic noise calcuRMW

5 Railverkeerslawaai Dutch railway noise calculation RMR

6 Harmonoise

7 SKM wegverkeerslawaai method lation method; both RMW-1981 and RMW-2012 (published on 1 juli 2015) method; both RMR-1996 and RMR-2012 (published on 1 juli 2015)

8 SKM railverkeer- SKM method for railway noise slawaai method calculation

Table 1: Noise calculation methods followed in Netherlands 
For modelling the inputs for industrial noise, we made an assumption that all the industrial noise sources are point sources e.g. forklifts, cranes and other machinery. We used only two objects i.e. buildings and noise barriers to see the variation in noise levels at different heights. The inputs are modelled in compliance with the Dutch industrial noise calculation method Industrielawaai IL. The method outlines several attributes that can be used as input for noise calculations e.g. surface sources, mobile sources, radiating roofs and radiating facades; however, for preliminary research, these are not taken into account. The calculation points where the noise levels are computed can be one or more individual point receivers placed on the building facades or can also be a grid of points in the area (Figure 4). Table 2 outlines the inputs selected for modelling industrial noise.

\begin{tabular}{llcl}
\hline$\#$ & Input & IL & RMW-2012 \\
\hline I & Sources & & \\
1 & Point sources & $\checkmark$ & $\checkmark$ \\
2 & Roads & - & \\
& & & \\
II & Objects & $\checkmark$ & $\checkmark$ \\
1 & Buildings & $\checkmark$ & \\
2 & Noise barriers & & \\
& & & $\checkmark$ \\
III & Calculation points & $\checkmark$ & $\checkmark$ \\
1 & Point receivers & $\checkmark$ & $\checkmark$ \\
2 & Grid & $\checkmark$ & \\
3 & Vertical grid & $\checkmark$ & $\checkmark$ \\
IV & Terrain & & $\checkmark$ \\
1. & Height points & $\checkmark$ & \\
\hline
\end{tabular}

Table 2: Inputs for industrial and road traffic noise

Case of Road traffic noise

Similarly, for road traffic noise, we only use roads as the noise source. Tramways are not taken into account. The inputs are modelled in compliance with the Dutch road traffic noise calculation method RMW- 2012. Table 2 outlines the inputs selected for modelling road traffic noise.

\subsection{Automatic generation of geographical inputs}

Study area

The study area is a part of a province in South Holland, the Netherlands and contains 42 buildings with an average height of 12 metres.

\section{Data \& software}

BGT (Basisregistratie Grootschalige Topografie) and AHN3 (Actueel Hoogtebestand Nederland v3) point cloud are used for generating the geographical inputs for noise simulation. BGT contains topographic data i.e. all the buildings, roads, railroads, rivers, lakes and canals, as well as other landscape elements like forests and most other artificial structures. AHN3 is the the national height model of the Netherlands and has point density $>10$ points $/ \mathrm{m}^{2}$. We used BGT and AHN3 to obtain the footprint and height of the topographic features, repectively. GeoMilieu ${ }^{4}$ software is used for computing the noise levels for industries and road traffic using the generated data in accordance with Dutch noise calculation methods. However, the study has one limitation with reference to

\footnotetext{
${ }^{4}$ https://dgmrsoftware.nl/geomilieu2.php
}

the availability of data related to noise sources. So, here we have used hypothetical noise data for simulation.

\section{Geographical input generation}

The open source 3D modelling software, $3 d f i e r^{5}$, is extended with functionalities to tailor the simulation inputs in the format required by GeoMilieu. 3dfier takes 2D topographic datasets and "3dfies" them (i.e. makes them 3D) by lifting every polygon to the required height. This height information is obtained from the point cloud data, and the semantics of every polygon are used to perform the lifting. For instance, water polygons are extruded to horizontal polygons, buildings to LOD1 blocks, roads as smooth surfaces, etc. The generated model is error-free with no holes (i.e. has watertight surfaces), where buildings are integrated in the surface, etc. The 3D city model of the study area is depicted in Figure 3. Since, GeoMilieu uses 2.5D geographical data for noise simulation, so we generated 2.5D models of buildings, terrain, roads, noise barriers (Figure $6 \&$ Figure 7). The height information of each feature type is stored as an attribute, thereby retaining the $3 \mathrm{D}$ information in the model itself for later reconstructing the simulation outputs in 3D. Table 3 highlights how the different the input features are created in this research.

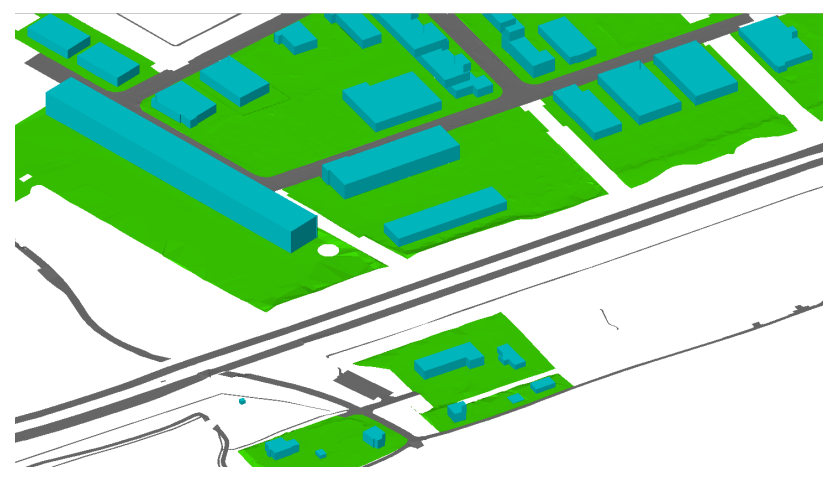

Figure 3: Generated 3D model of the study area

\begin{tabular}{lllll}
\hline$\#$ & Input & Methodology & $\begin{array}{l}2.5 \mathrm{D} \\
\text { Geometry }\end{array}$ & $\begin{array}{l}\text { 3D } \\
\text { Geometry }\end{array}$ \\
\hline 1 & Buildings & $\begin{array}{l}\text { BGT building poly- } \\
\text { gons + Height from } \\
\end{array}$ & Polygons & Solids \\
& & & \\
& & AHN3 point cloud & &
\end{tabular}

2 Roads

BGT road polygons

Polygons

Multisurfaces

+ Height from

3 Terrain

BGT terrain poly-
gons + Height from
AHN3 point cloud

Points/-

TIN AHN3 point cloud

Curves

(Triangulated Irregular Network)

4 Noise

BGT noise barrier barriers

curves + Height

Curves

Multisurfaces

from AHN3 point

cloud

Table 3: Inputs for industrial and road traffic noise

Apart from these, some other data was generated:

1. Fictituous data for industrial noise point sources (Figure 7).

2. A $10 \mathrm{mX} 10 \mathrm{~m}$ horizontal grid at $4 \mathrm{~m}$ height (prescribed by END) of the sample area for calculating noise.

\footnotetext{
${ }^{5}$ https://github.com/tudelft3d/3dfier
} 

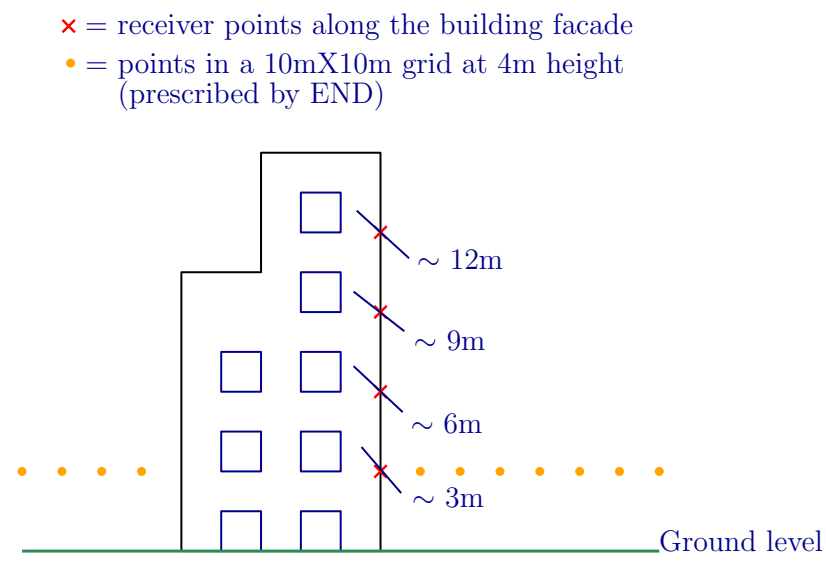

Figure 4: Placement of noise calculation points along the building facade and in a grid

3. In GeoMilieu, calculation of noise levels is possible up to 6 height values at a particluar location. In the Netherlands, height of 3 metres is roughly equal to the height of one floor of a building (Gemiddeld, 2014). The average height of buildings in the study area is 12 metres. So, receiver points are placed along the building facades vertically separated by a distance of 3 metres (see Figure 4).

\section{MODELLING NOISE IN 3D}

\subsection{Current CityGML Noise ADE}

CityGML has the concept of ADE (Application Domain Extension) to extend its schema with new classes and objects. ADEs ensure semantic and syntactic interoperability for the exchange of application specific information. ADEs are increasingly being used in creating application specific extensions e.g. for energy modelling (Nouvel et al., 2015), modelling topographic data (Brink et al., 2013), indoor modelling (Kim et al., 2014), etc. The application schema which we focus here is Noise ADE (Groger et al., 2012). For the current Noise ADE, three existing CityGML modules (Transportation, Building, CityFurniture) were extended to include noise data in CityGML. Transportation module contains new classes e.g. NoiseRoadSegment and NoiseRailwaySegment which are the segments of roads and railway lines (Figure 8). These objects have their own set of attributes e.g. traffic flow, speed limits, surface type, crossings, bridges, etc. The geometry of these objects is derived from their respective parent classes: Road and Railway. It also contains a new feature type Train with attributes like train type, its speed, etc. to store the information about individual trains.

The Building module was extended to include noise attributes related to existing buildings e.g. reflection from buildings, noise levels observed during the day and night, number of people living in the buildings, etc. (Figure 5). Similary, the CityFurniture module contains new class NoiseCityFurnitureSegment with new attributes for noise. All these noise attributes are derived based on the regulations issued by the Federal Government of Germany in accordance with END.

\subsection{Our solution: Extended Noise ADE}

We observed some limitations in the current noise ADE:

1. It deals only with the noise caused by road traffic and railways.

2. It does not support industrial noise.

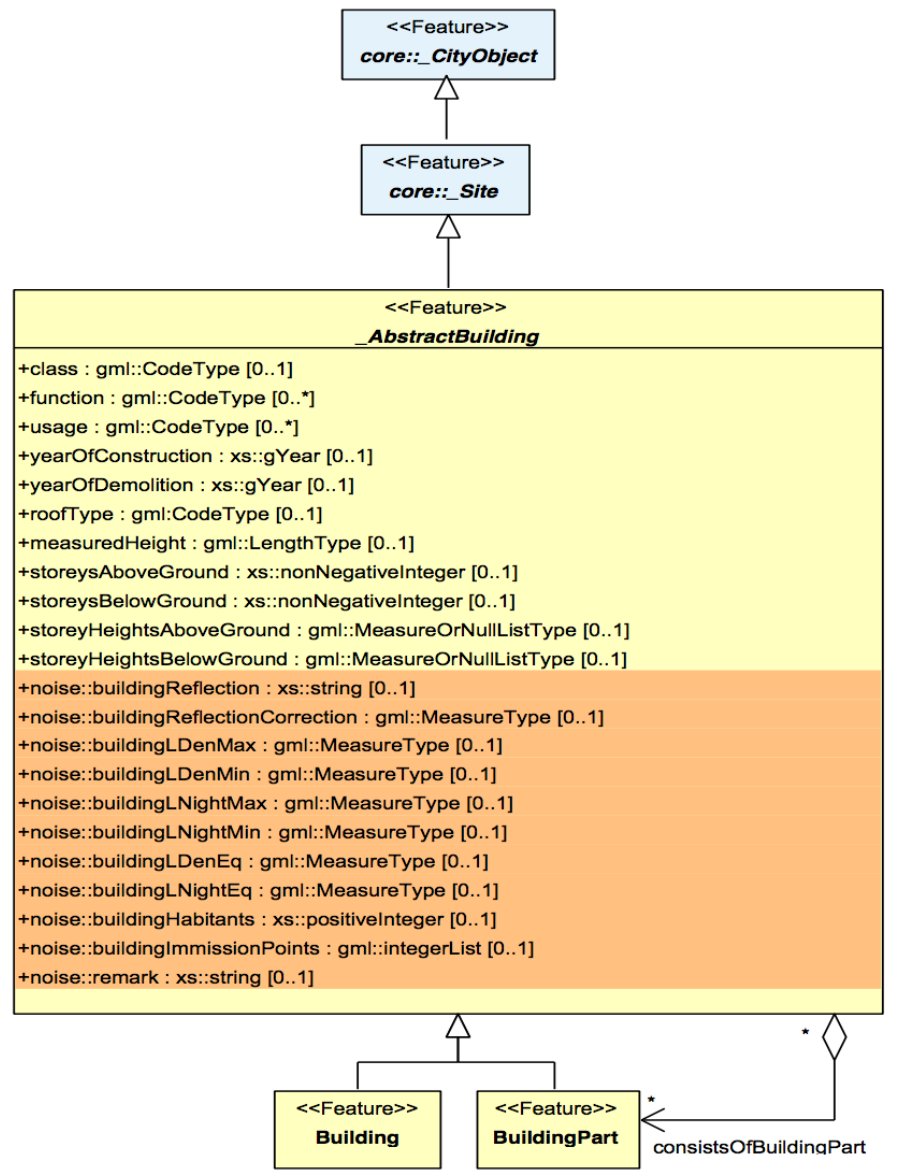

Figure 5: CityGML Noise ADE UML for buildings (light yellow=CityGML Transportation module, light orange $=$ CityGML Noise ADE) (Groger et al., 2012)

3. For detailed noise analysis, the current noise attributes are not sufficient to map the noise levels over the wide frequency range i.e. the 9 octave bands.

4. No information is stored about the noise barriers.

5. No distinction in the speeds of different type vehicles e.g. motor cycles, light vehicles and heavy vehicles.

Our approach aims at supplementing the current Noise ADE by introducing new objects and attributes to represent the missing information. This section presents our approach used for modelling road and industrial noise in the current Noise ADE. There are different ways to add application information in a CityGML ADE. Brink et al. (2013) describes six alternatives for modelling ADEs in UML. One way is to model it directly by adding new attributes in the already exisitng CityGML classes. We adopt the approach of adding application specific properties by introducing subclasses in the schema. The extended Noise ADE can be accessed at https://github.com/kkimmy/eNoiseADE. Four main changes are introduced in existing CityGML Noise ADE:

1. As the current Noise ADE lacked information about the noise barriers, we introduced a new feature type NoiseBarrier with gml:MultiSurface geometry in the ADE to model them.

2. Similarly, for industrial noise, we introduced a new feature type IndustrialPointSource with gml: Point geometry to model the location of industrial noise sources (Figure 10). The thematic data associated with the noise sources like operating hours and emissions are modelled as attributes of 
this new feature type.

3. For roads, we did not introduce any new class but merged the already exisiting noise attributes with the new and extensive semantic data about the speed, traffic flow and emissions of light and heavy vehicles separately (Figure 10).

4. For storing the noise levels computed on buildings facades, we introduced a new subclass of Building module BuildingNoise (Figure 9). Apart from the already exisitng attributes, it has new attributes for storing the information about the receiving surface, value of reflection factors, and noise levels at 6 different heights and at a wide range of frequencies during the day, evening and night.

\section{CONCLUSION \& FUTURE WORK}

Monitoring and mapping of noise is an active area of research which is drawing substantial public attention. The noise maps are useful in labeling noise affected areas in an urban setting. 3D noise maps are easy to understand and can prove beneficial in the process of city planning and management as they provide the possiblity of visualizing the analysed information in 3D. In this paper, we have described our approach for creating the input data for noise simulations and presenting the results in 3D using CityGML. The output of any noise study is sensitive to input data used in simulations. At present, a universal and automated method to create inputs for noise calculations does not exist. Most of the work of data creation is done semi-automatically (and sometimes even manually) which is very time consuming. Moreover, there is no uniformity in input data, therefore it is difficult to compare the results of different noise studies. This research is a steping stone in the direction of standardising the data used for noise studies and for reconstructing the 3D outputs accordingly. For simplicity, we used only roads and industrial point sources as inputs in this research. In future research, we aim to extend our approach for input creation to implement different types of noise sources and topographic objects used by the noise calculation models e.g. tramways, mobile sources, railways, etc. We also plan to implement them in the Noise ADE schema to create a semantically rich and interoperable noise database. Future research work also includes visualizing these noise outputs in 3D on web.

\section{ACKNOWLEDGEMENTS (OPTIONAL)}

This project (Project\# 13740) is supported by the Netherlands Organisation for Scientific Research (NWO), and which is partly funded by the Ministry of Economic Affairs. Special thanks to DGMR, The Hague for providing inputs for data modelling and licence of GeoMilieu software for research.

\section{References}

Adriana Stuijt, 2009. Noise pollution kills 600 Dutch a year. http: //www.digitaljournal.com/article/267835. (Last accessed: Apr 11, 2017).

Brink, L., Stoter, J. and Zlatanova, S., 2013. UML-based approach to developing a CityGML Application Domain Extension. Transactions in GIS 17(6), pp. 920-942.
Butler, D., 2004. Noise management: sound and vision. Nature 427(6974), pp. 480-481.

Czerwinski, a., Sandmann, S., Stöcker-Meier, E. and Plümer, L., 2007. Sustainable SDI for EU noise mapping in NRW ? best practice for INSPIRE *. International Journal of Spatial Data Infrastructures Research 2(July), pp. 90-111.

Daikin Applied, 2014. HVAC Acoustic Fundamentals Application Guide AG 31-010 (01/04). http: //lit.daikinapplied.com/bizlit/documentstorage/ aircooledchiller/applicationguides/ag31-010_ hvac_acoustic_fundamentals.pdf. (Last accessed: June 09, 2017).

de Kluijver, H. and Stoter, J., 2003. Noise mapping and gis: optimising quality and efficiency of noise effect studies. Computers, Environment and Urban Systems 27(1), pp. 85-102.

Den Boer, L. and Schroten, A., 2007. Traffic noise reduction in europe. CE Delft 14, pp. 2057-2068.

Directive, E., 2002. Directive 2002/49/EC of the European parliament and the Council of 25 June 2002 relating to the assessment and management of environmental noise. Official Journal of the European Communities, L.

Gemiddeld, 2014. Gemiddelde hoogte plafond. http: //gemiddeldgezien.nl/gemiddelde-hoogte-plafond. (Last accessed: Apr 28, 2017).

Groger, G., Kolbe, T. H., Nagel, C. and Häfele, K.-H., 2012. OGC City Geography Markup Language (CityGML) Encoding Standard version 2.0.0.

Kim, Y., Kang, H. and Lee, J., 2014. Developing CityGML Indoor ADE to manage indoor facilities. In: Innovations in 3D Geoinformation sciences, Springer, pp. 243-265.

Law, C.-w., Lee, C.-k., Lui, A. S.-w., Yeung, M. K.-1. and Lam, K.-c., 2011. Advancement of three-dimensional noise mapping in Hong Kong. Applied Acoustics 72(8), pp. 534-543.

Nouvel, R., Bahu, J.-M., Kaden, R., Kaempf, J., Cipriano, P., Lauster, M., Haefele, K.-H., Munoz, E., Tournaire, O. and Casper, E., 2015. Development of the citygml application domain extension energy for urban energy simulation. In: 14th international conference of the international building performance simulation association (ibpsa). Retrieved from http://www. bs2015. in/files/BS2015 Proceeding. pdf.

Stadler, A. and Kolbe, T. H., 2007. Spatio-semantic coherence in the integration of 3D city models. In: Proceedings of the 5th International Symposium on Spatial Data Quality, Enschede.

Stoter, J., De Kluijver, H. and Kurakula, V., 2008. 3D noise mapping in urban areas. International Journal of Geographical Information Science 22(8), pp. 907-924.

VROM, 1981. Handleiding meten en rekenen industrielawaai, report nr. Technical report, Minister van Volkshuisvesting, Ruimtelijke Ordening en Milieubeheer.

VROM, 2015. Reken- en meetvoorschrift geluidhinder 2012, bijlage iii. Technical report, Minister van Volkshuisvesting, Ruimtelijke Ordening en Milieubeheer. 


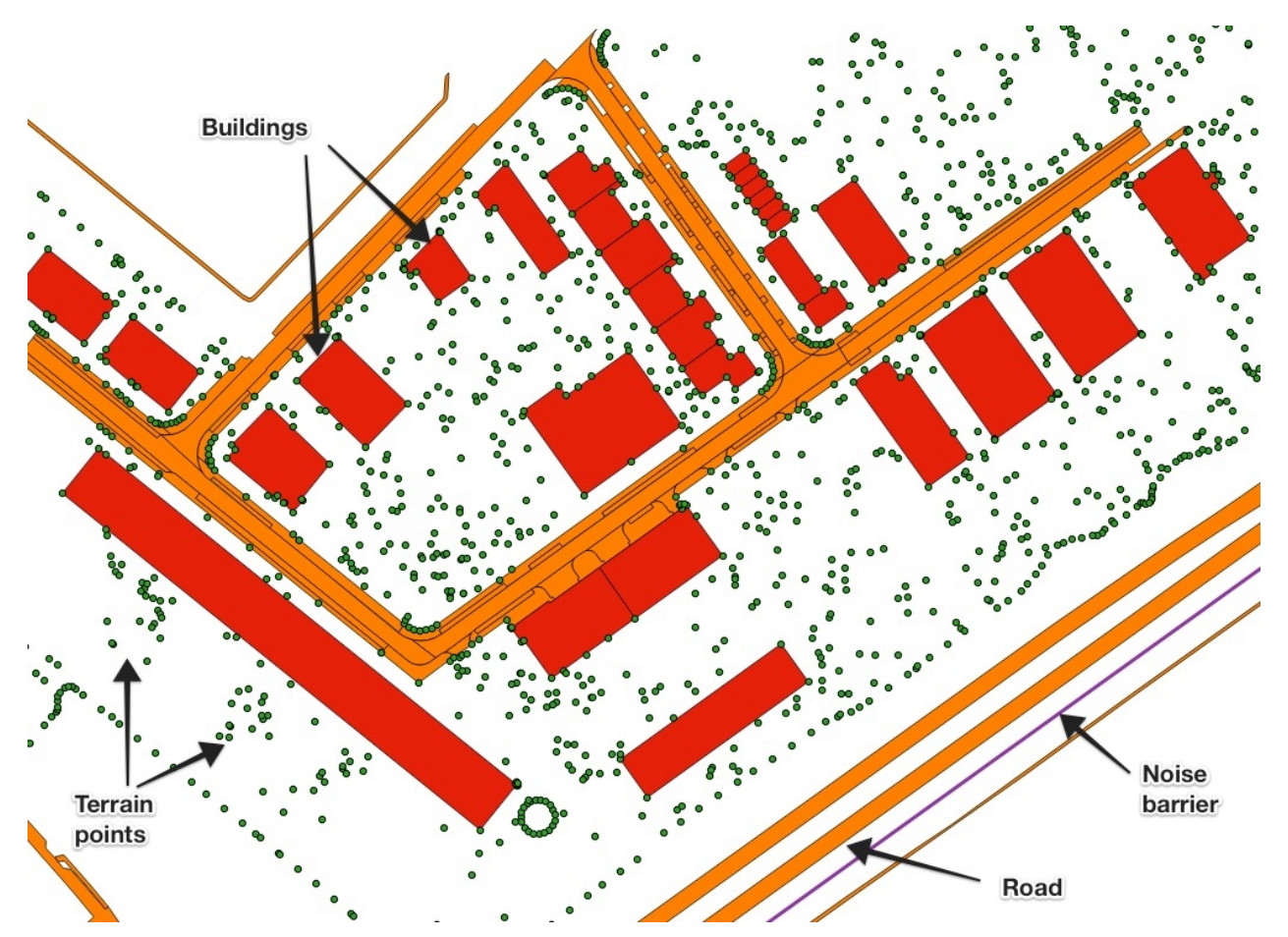

Figure 6: Generated 2.5D input model for road traffic noise

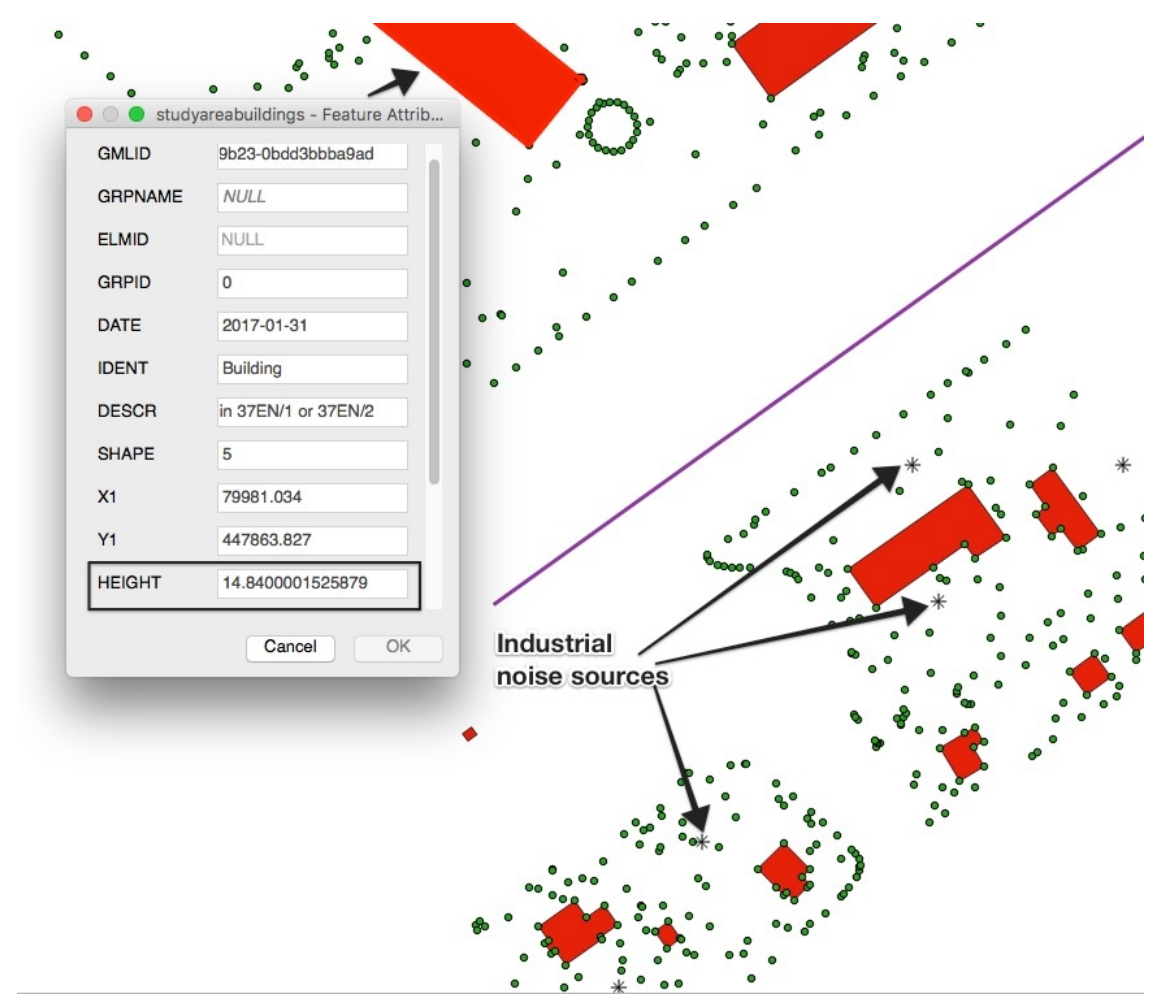

Figure 7: $2.5 \mathrm{D}$ input model for industrial noise with fictitious noise sources.(Height of the feature is stored as attribute to reconstruct the 3D geometry in output model) 


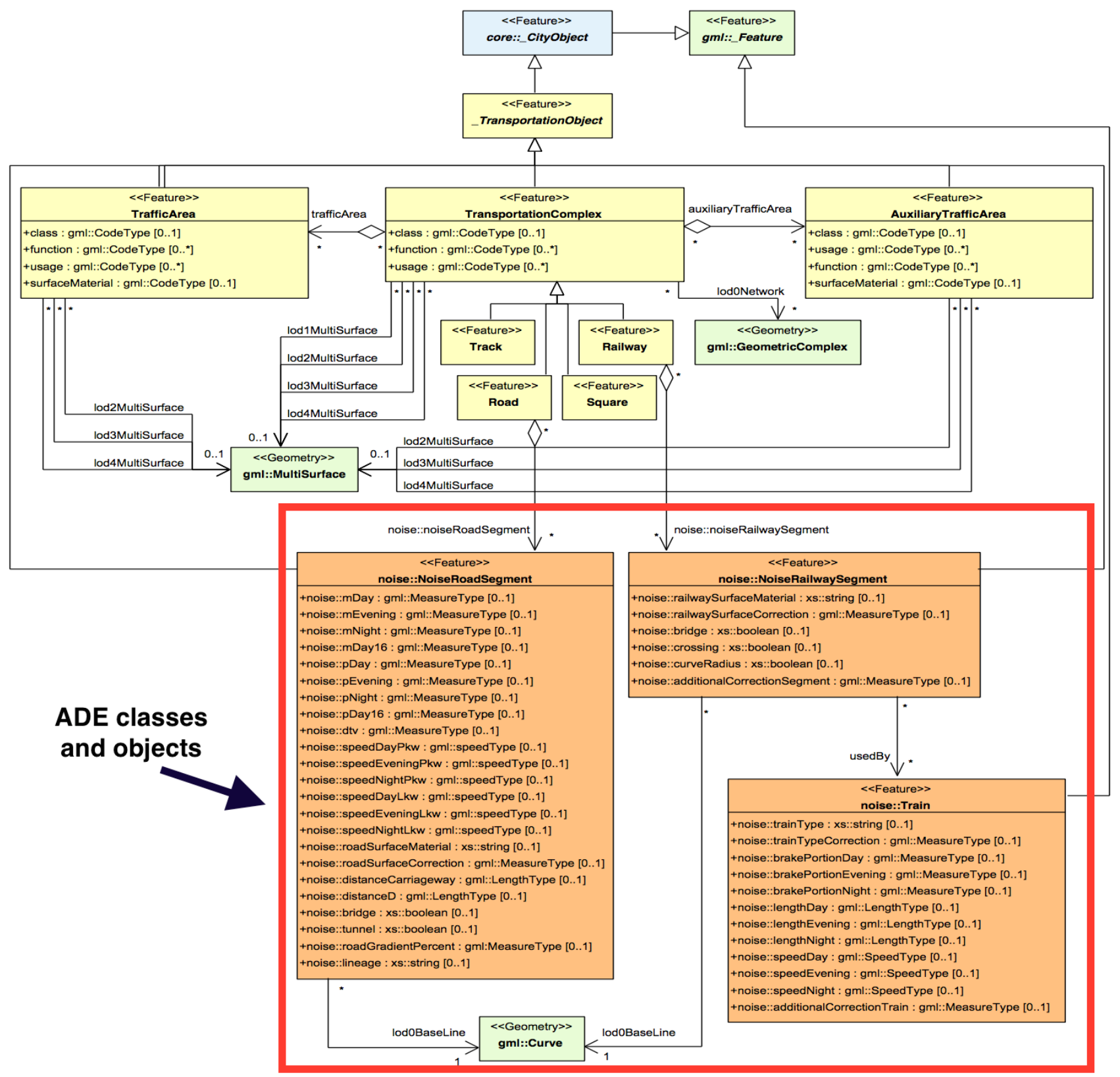

Figure 8: CityGML Noise ADE UML for roads and railways(light yellow=CityGML Transportation module, light orange=CityGML Noise ADE) (Groger et al., 2012) 


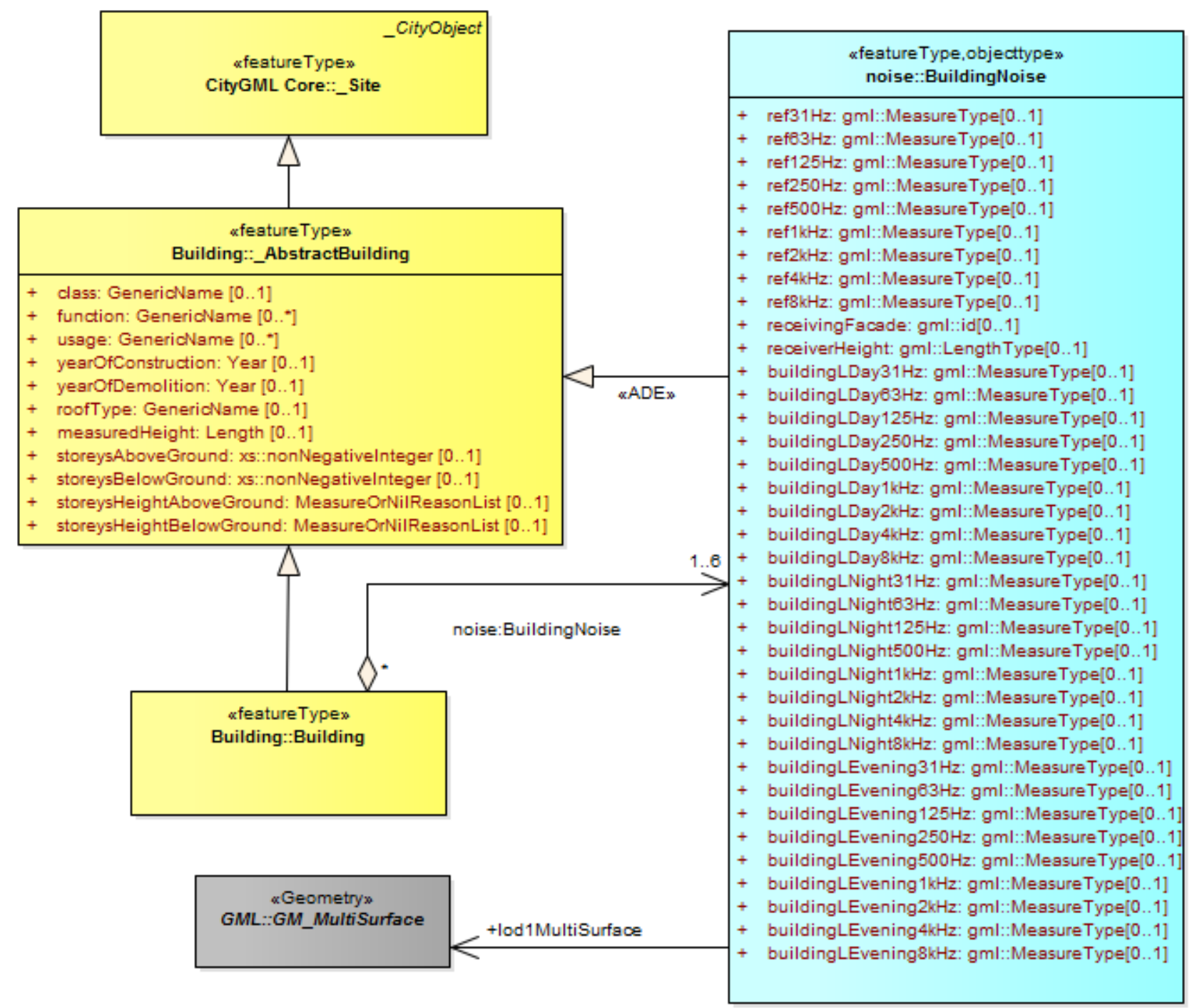

Figure 9: Extended CityGML Noise ADE UML for buildings (light yellow=CityGML Transportation module, light blue=Extended CityGML Noise ADE) (We removed the existing noise attributes for easy understanding.) 


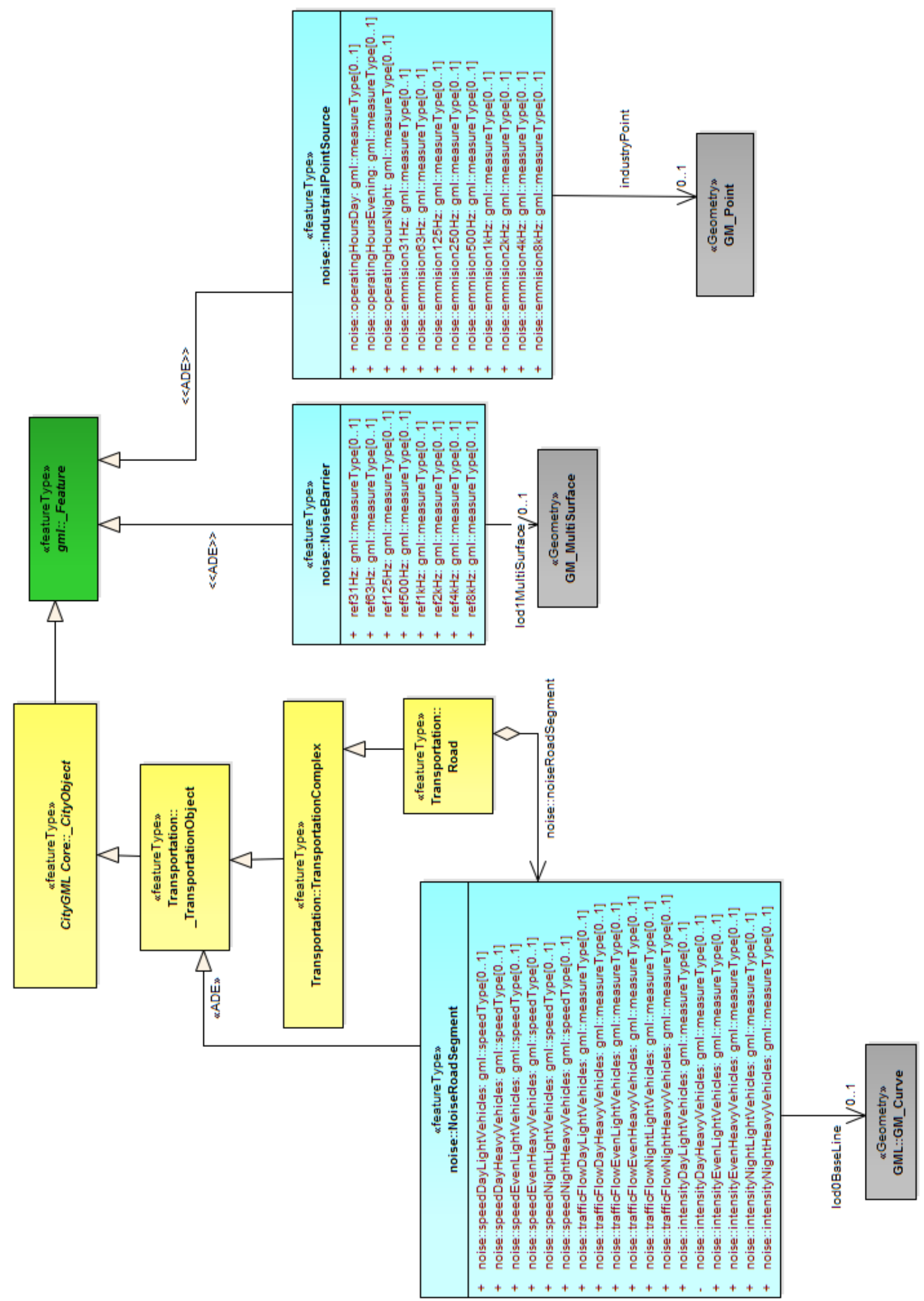

Figure 10: Extended CityGML Noise ADE UML for road and industrial noise (light yellow=CityGML Transportation module, light blue=Extended CityGML Noise ADE)(We removed the existing noise attributes for easy understanding.) 